\title{
Evaluating an undergraduate interprofessional simulation-based educational module: communication, teamwork, and confidence performing cardiac resuscitation skills
}

\author{
This article was published in the following Dove Press journal: \\ Advances in Medical Education and Practice \\ 4 November 2010 \\ Number of times this article has been viewed
}

\author{
Marian Luctkar-Flude' \\ Cynthia Baker' \\ Cheryl Pulling' \\ Robert McGraw ${ }^{2}$ \\ Damon Dagnone 2 \\ Jennifer Medves' \\ Carly Turner-Kelly' \\ 'School of Nursing, Queen's \\ University, Kingston, Ontario, \\ Canada; ${ }^{2}$ School of Medicine, Queen's \\ University, Kingston, Ontario, Canada
}

Correspondence: Marian Luctkar-Flude Queen's University, School of Nursing,

92 Barrie Street, Kingston,

ON K7L 3N6, Canada

Tel + I 6135336000 , ext 77383

Fax +I 6135336770

Email mflI@queensu.ca
Purpose: Interprofessional (IP) collaboration during cardiac resuscitation is essential and contributes to patient wellbeing. The purpose of this study is to evaluate an innovative simulation-based IP educational module for undergraduate nursing and medical students on cardiac resuscitation skills.

Methods: Nursing and medical trainees participated in a new cardiac resuscitation curriculum involving a 2-hour IP foundational cardiac resuscitation skills lab, followed by three 2-hour IP simulation sessions. Control group participants attended the existing two 2-hour IP simulation sessions. Study respondents $(\mathrm{N}=71)$ completed a survey regarding their confidence performing cardiac resuscitation skills and their perceptions of IP collaboration.

Results: Despite a consistent positive trend, only one out of 17 quantitative survey items were significantly improved for learners in the new curriculum. They were more likely to report feeling confident managing the airway during cardiac resuscitation $(P=0.001)$. Overall, quantitative results suggest that senior nursing and medical students were comfortable with IP communication and teamwork and confident with cardiac resuscitation skills. There were no significant differences between nursing students' and medical students' results. Through qualitative feedback, participants reported feeling comfortable learning with students from other professions and found value in the IP simulation sessions.

Conclusion: Results from this study will inform ongoing restructuring of the IP cardiac resuscitation skills simulation module as defined by the action research process. Specific improvements that are suggested by these findings include strengthening the team leader component of the resuscitation skills lab and identifying learners who may benefit from additional practice in the role of team leader and with other skills where they lack confidence.

Keywords: interprofessional education, undergraduate education, medical education, nursing education, simulation

\section{Introduction}

The Queen's University Faculty of Health Sciences Patient Simulation Lab is the setting for an innovative pilot project to enhance patient welfare and safety by creating and implementing interprofessional (IP) health education modules using human patient simulators. High-fidelity simulation has been shown to be effective and satisfying in health sciences education for learning new skills and practicing team approaches to managing complex care. ${ }^{1}$

As IP teamwork is essential for effective cardiac resuscitation, we piloted the project within an action research framework by introducing IP cardiac resuscitation rounds 
for pre-licensure medical and nursing students. Consistent with action research, evaluation of this pilot generated the development of a simulation-based cardiac resuscitation curriculum for medical and nursing trainees. It includes a preparatory IP foundational lab on cardiac resuscitation skills followed by participation in three sessions of IP resuscitation rounds.

Cardiac resuscitation is a low frequency, but high risk, event that is often anxiety provoking for health professionals. Moreover, it is difficult for health professionals to develop and maintain the skills needed to perform competently. ${ }^{2,3}$ Health care professionals in general have been reported to display poor cardiopulmonary resuscitation (CPR) skills and have many educational inadequacies. ${ }^{3-5}$ Patient simulation is increasingly being recommended and used to teach, reinforce, and evaluate basic cardiac life support (BCLS) and advanced cardiac life support (ACLS) skills for post-licensure health professionals. ${ }^{6-12}$ Simulation training has also been linked to improved provider resuscitation performance $^{13}$ and positive patient outcomes following cardiac arrest. ${ }^{14}$

Studies of undergraduate nursing and medical students have found a lack of educational preparation leading to low self-confidence and poor performance of BCLS skills., ${ }^{3,15,16}$ Use of patient simulation in undergraduate education has been associated with increased retention of CPR skills in nursing students and greater competence in emergency management for medical students. . $^{3,17,18}$

Traditionally, clinical education for health professional learners has been uniprofessional, ${ }^{19}$ even though commonly, the competencies they are learning will be carried out in IP teams. The focus of IP education is to teach learners about the roles of other health professionals and the key behaviors essential to health care team functioning. ${ }^{20}$ In addition, team training has been proposed as a strategy to reduce medical errors and improve patient safety. ${ }^{21}$

Simulation is increasingly being used in multidisciplinary training of post-licensure practitioners. IP team training for emergency medical teams using simulation has been shown to improve team performance by improving efficiency as team members assume specific roles and perform delineated tasks, resulting in improved completion of specified tasks and simulated outcomes; ${ }^{22}$ however, only three studies were retrieved describing the use of simulation for IP cardiac resuscitation training or teamwork training for undergraduate nursing and medical students, and of these, only one reported using high-fidelity simulation. In the first study, using lowfidelity simulation, there was no difference found between
IP and uniprofessional teams for leadership, team dynamics or resuscitation task performance, but the IP groups retained a positivity towards IP education at 3-4 months following intermediate life support cardiac arrest scenarios. ${ }^{23}$ In the second study, peer-led multidisciplinary resuscitation training for health care students provided a quality of education that was at least as good as that provided by clinical staff while providing undergraduate health care students with the opportunity to develop teaching skills in multiprofessional groups. ${ }^{24}$

The only study reporting the use of high-fidelity patient simulation for IP undergraduate resuscitation training was one conducted in our own patient simulation lab, on the introduction of the IP cardiac resuscitation rounds in $2005 .{ }^{25}$ Surveys of learners to evaluate our pilot project indicated that the cardiac resuscitation rounds were rated highly by nursing and medical trainees as valuable learning experiences that increased their understanding of team roles in resuscitation. Participants also felt that these sessions should be mandatory for all nursing and medical students, and requested additional IP training. Focus-group findings and anecdotal feedback from instructors indicated, however, that many learners were not well prepared when they arrived to participate in the rounds. Moreover, learners arrived with an inconsistent skill set. Observations of the rounds revealed that considerable time was spent reviewing basic cardiac resuscitation skills rather than practicing IP teamwork in resuscitation scenarios. In light of these findings, it was proposed that nursing and medical students be given the opportunity to review basic cardiac resuscitation skills prior to resuscitation rounds so that all participants would arrive with a shared, foundational skill set and be prepared to immediately take part in the simulation scenarios.

Evaluation of the IP cardiac resuscitation curriculum is being conducted within the action research framework of our larger project to optimize the effectiveness of our approach. Objectives of the curriculum include increased learner confidence when confronting cardiac resuscitation events and increased learner confidence in their ability to collaborate in an IP team. The purpose of this study is to evaluate learners' confidence in their ability to perform cardiac resuscitation skills and their comfort with IP communication and teamwork. Evaluation of their performance of cardiac resuscitation skills is in progress and will be reported elsewhere.

\section{Methods \\ Design}

Mixed methods are being used within the framework of the larger action research project to evaluate modules as they 
are implemented and also following module development resulting from earlier evaluations. In the fall term of 2008, 4th-year nursing and medical students participated in the new cardiac resuscitation curriculum consisting of a 2-hour foundational IP cardiac resuscitation skills lab, followed by three 2-hour IP resuscitation rounds using high-fidelity patient simulators. Junior emergency medicine residents also attended the IP resuscitation rounds but are not included in the evaluation sample. Learners in the spring and summer term of 2008 who participated in the initial cardiac resuscitation rounds pilot project format, consisting of two 2-hour resuscitation rounds sessions, served as the control group.

The components of the foundational skills lab include a review of airway management, a review of intravenous initiation, resuscitation drugs, and defibrillation. Nursing and medical students rotate through the various stations in IP groups of five. During the last twenty minutes of the skills lab, instructors lead the students through at least two simple ventricular fibrillation cardiac arrest scenarios using the high-fidelity patient simulators. Each time the patient is resuscitated successfully after one or two defibrillations. The purpose of these scenarios is to clarify the various team member roles including the team leader role.

The three resuscitation rounds sessions involve hands-on team responses to more complex high-fidelity simulations of cardiac resuscitation scenarios including witnessed and unwitnessed ventricular fibrillation, ventricular tachycardia (with and without a pulse), symptomatic bradycardia, asystole, and pulseless electrical activity. Nursing and medical students rotate through the various team roles, including the team leader role. Instructors from the School of Medicine and the School of Nursing serve as facilitators for the sessions and lead learners through debriefing sessions following each scenario, focusing on team performance of the cardiac resuscitation.

Following the last resuscitation round (third for the new cardiac resuscitation curriculum; second for the control group) learners were asked to complete a written survey package with both quantitative and qualitative instruments.

\section{Sample}

A total convenience sample of 70 nursing and medical trainees participated in the new cardiac resuscitation curriculum in the fall of 2008; 34 participated in the pilot resuscitation rounds in the spring/summer term of 2008. Of the total 104 learners, 51 learners in the new curriculum, and 21 in the control group completed the survey.

\section{Instruments}

Survey participants were asked to indicate whether they were from nursing or medicine, their date of birth, and their gender, and then to respond to three instruments.

\section{Communication and teamwork}

A quantitative survey was developed by the Office of Interprofessional Education and Practice (OIPEP), with questions abstracted from the Communication and Teamwork Scale of the West of England, Bristol Entry Level Interprofessional Questionnaire. ${ }^{26}$ The survey consisted of nine items on a six-point Likert scale related to comfort with IP communication. Negative statements were reverse scored such that higher scores on each item indicated greater comfort with communication and teamwork items. Internal consistency for the scale was good (Cronbach's alpha $=0.793)$.

\section{Confidence performing cardiac resuscitation skills}

A second quantitative instrument was developed by project team members including the project coordinator from the School of Nursing and members of OIPEP. It consists of 8 items on a six-point Likert scale measuring learner confidence related to performing cardiac resuscitation skills targeted by the course objectives. Higher scores are indicative of higher confidence with the associated skills. Internal consistency for the scale was good (Cronbach's alpha $=0.763$ ). Validity was established through peer review by the laboratory and clinical instructors teaching in the course.

\section{IP learning}

A qualitative questionnaire was developed by the project team asking students to respond to four open-ended questions related to their comfort with IP learning, challenges and benefits to IP learning, and suggestions to improve the IP cardiac resuscitation educational module.

\section{Data analysis}

Quantitative data were entered into an SPSS 17.0 database and verified by a second person. Standard univariate measures such as means (Ms), standard deviations (SDs), and medians were calculated to describe the outcomes. Comparisons of groups were conducted using independent $t$-tests for scale data and Mann-Whitney U test for ordinal data. Qualitative data analysis was completed using thematic analysis of responses.

\section{Ethics}

This study received approval from the Queen's University Health Sciences Research Ethics Board. Informed consent was obtained from all study participants. 


\section{Results}

A total of 71 learners out of 104 completed the study survey package after attending their last session of the resuscitation rounds for an overall response rate of $69.2 \%$. A breakdown of the learners in the new cardiac resuscitation curriculum and the control group is presented in Table 1. The respondents in the new curriculum $(\mathrm{N}=50)$ consisted of 30 nursing and 20 medical trainees. Their average age was 25 years, with 11 males and 39 females. Respondents in the control group $(\mathrm{N}=21)$ consisted of 5 nursing and 16 medical trainees. The average age of control group respondents was 28 years, with 7 males and 14 females.

\section{Communication and teamwork}

Results of the Communication and Teamwork questionnaire are presented in Table 2. Overall, the majority of learners in both the control and experimental groups reported being comfortable communicating and collaborating within a team. The mean scores for learners in the new cardiac resuscitation curriculum indicated greater comfort with IP communication and teamwork than mean scores for the control group for seven out of the nine survey items; however, the differences observed between the two groups were not statistically significant. The mean total comfort with communication and teamwork score was higher for the experimental group $(\mathrm{M}=51.76 ; \mathrm{SD}=2.84)$ than for the control group $(\mathrm{M}=50.15 ; \mathrm{SD}=5.26)$, but again the differences were not statistically significant, and the effect size was small (Cohen's $d=0.381$ ). A sample size of 100 in each group would be required to detect a significant difference between the groups with a power of $80 \%$. There was no significant difference in their mean total self-confidence scores between medical students $(\mathrm{M}=51.56 ; \mathrm{SD}=4.44)$ and nursing students $(\mathrm{M}=51.06 ; \mathrm{SD}=2.83)$.

Table I Survey respondent rates

\begin{tabular}{llll}
\hline & $\begin{array}{l}\text { Number } \\
\text { of learners }\end{array}$ & $\begin{array}{l}\text { Number } \\
\text { of survey } \\
\text { respondents }\end{array}$ & $\begin{array}{l}\text { Response } \\
\text { rate }\end{array}$ \\
\hline $\begin{array}{l}\text { Pilot cardiac } \\
\text { resuscitation rounds } \\
\text { (control group): }\end{array}$ & & & \\
$\quad$ Nursing & 11 & 5 & $45.5 \%$ \\
$\quad$ Medicine & 23 & 16 & $69.6 \%$ \\
$\quad$ Total interprofessional & 34 & $\mathbf{2 1}$ & $\mathbf{6 1 . 8 \%}$ \\
$\begin{array}{l}\text { New cardiac } \\
\text { resuscitation curriculum }\end{array}$ & & & \\
(experimental group): & 33 & & \\
$\quad$ Nursing & 37 & 20 & $93.9 \%$ \\
$\quad \begin{array}{l}\text { Medicine } \\
\text { Total interprofessional }\end{array}$ & $\mathbf{7 0}$ & $\mathbf{5 1}$ & $\mathbf{7 0 . 0 \%}$ \\
Total participants & 104 & $\mathbf{7 2}$ & $69.2 \%$ \\
\hline
\end{tabular}

\section{Confidence performing cardiac resuscitation skills}

Results of the Confidence Performing Cardiac Resuscitation Skills survey are presented in Table 3. Mean scores for the learners in the new cardiac resuscitation curriculum were higher than those for the control group for five out of the eight survey items). They were significantly more likely to report that they felt confident managing the airway during cardiac resuscitation $(P=0.001)$. There were no other statistically significant differences between the two groups for the remaining seven survey items. The mean total self-confidence score was higher for the experimental group $(\mathrm{M}=37.73 ; \mathrm{SD}=4.35)$ than for the control group $(\mathrm{M}=35.95 ; \mathrm{SD}=5.60)$ but there was no significant difference between the two groups, and the effect size was small (Cohen's $d=0.356$ ). A sample size of 121 in each group would be required to detect a significant difference between the groups with a power of $80 \%$.

Overall, the majority of learners reported being at least somewhat confident in performing all of the skills; however, many learners reported being at least somewhat unconfident being the team leader in a cardiac resuscitation (26.7\%), assessing basic cardiac rhythms (14.1\%), starting an intravenous feed during cardiac resuscitation (21.2\%), and administering cardiac resuscitation medications (22.6\%). There was no significant difference in their mean total self-confidence scores between medical students ( $\mathrm{M}=37.03 ; \mathrm{SD}=5.19)$ and nursing students $(\mathrm{M}=37.43 ; \mathrm{SD}=4.34)$.

\section{IP learning}

Qualitative results are summarized under each of the survey questions below. In general, students in both groups reported enjoying the IP simulation sessions on cardiac resuscitation.

1. Explain how comfortable you are/would feel learning with students of different professions and/or levels of education?

The majority of learners in both groups indicated that they felt comfortable or very comfortable learning with students of different professions and/or education levels. Some learners in the control group said they would feel "intimidated because of a lack of knowledge", whereas some learners in the new cardiac resuscitation curriculum felt that the students with the "higher knowledge base could help us out" and reported that they were "nervous at first, but got better as time progressed".

2. Do you think there are/would be any challenges and/or benefits from learning resuscitation skills alongside students of a different profession? 
Table 2 Learner comfort with interprofessional communication and teamwork

\begin{tabular}{|c|c|c|c|c|c|c|}
\hline Survey item & $\begin{array}{l}\text { Overall } \\
\text { mean score } \\
(\mathrm{SD}) \\
\mathbf{N}=7 \mathbf{I}\end{array}$ & $\begin{array}{l}\text { Control group } \\
\text { mean score } \\
\text { (SD) } \\
N=21\end{array}$ & $\begin{array}{l}\text { New cardiac } \\
\text { resuscitation group } \\
\text { mean score } \\
(\mathrm{SD}) \\
\mathrm{N}=\mathbf{5 0}\end{array}$ & $\begin{array}{l}\text { Mann- } \\
\text { Whitney U }\end{array}$ & $\mathbf{Z}$ & $\begin{array}{l}\text { Asymp sig } \\
\text { (2-tailed) }\end{array}$ \\
\hline $\begin{array}{l}\text { Comfortable justifying } \\
\text { recommendations with } \\
\text { more senior people. }\end{array}$ & $\begin{array}{l}4.58 \\
(0.839)\end{array}$ & $\begin{array}{l}4.29 \\
(0.717)\end{array}$ & $\begin{array}{l}4.70 \\
(0.863)\end{array}$ & 373.500 & -1.897 & 0.058 \\
\hline $\begin{array}{l}\text { Comfortable explaining an issue } \\
\text { to people unfamiliar with the topic. }\end{array}$ & $\begin{array}{l}4.86 \\
(0.661)\end{array}$ & $\begin{array}{l}4.76 \\
(0.700)\end{array}$ & $\begin{array}{l}4.90 \\
(0.647)\end{array}$ & 455.500 & -0.813 & 0.416 \\
\hline $\begin{array}{l}\text { Difficulty adapting my communication } \\
\text { style to particular situations } \\
\text { and audiences. }\end{array}$ & $\begin{array}{l}4.37 \\
(1.124)\end{array}$ & $\begin{array}{l}4.35 \\
(1.155)\end{array}$ & $\begin{array}{l}4.37 \\
(1.123)\end{array}$ & 508.000 & -0.027 & 0.978 \\
\hline $\begin{array}{l}\text { Prefer to stay quiet when other } \\
\text { people express opinions } \\
\text { that I don't agree with. }\end{array}$ & $\begin{array}{l}4.34 \\
(1.133)\end{array}$ & $\begin{array}{l}4.30 \\
(0.796)\end{array}$ & $\begin{array}{l}4.35 \\
(1.255)\end{array}$ & 469.000 & -0.544 & 0.586 \\
\hline $\begin{array}{l}\text { Comfortable working } \\
\text { in a group. }\end{array}$ & $\begin{array}{l}5.18 \\
(0.780)\end{array}$ & $\begin{array}{l}5.14 \\
(1.014)\end{array}$ & $\begin{array}{l}5.20 \\
(0.670)\end{array}$ & 484.000 & -0.368 & 0.713 \\
\hline $\begin{array}{l}\text { Uncomfortable expressing } \\
\text { personal opinions in a group. }\end{array}$ & $\begin{array}{l}4.11 \\
(1.280)\end{array}$ & $\begin{array}{l}4.21 \\
(1.005)\end{array}$ & $\begin{array}{l}4.07 \\
(1.38)\end{array}$ & 470.500 & -0.192 & 0.848 \\
\hline $\begin{array}{l}\text { Uncomfortable taking the } \\
\text { lead in a group. }\end{array}$ & $\begin{array}{l}4.13 \\
(1.329)\end{array}$ & $\begin{array}{l}4.15 \\
(1.309)\end{array}$ & $\begin{array}{l}4.11 \\
(1.350)\end{array}$ & 472.000 & -0.170 & 0.865 \\
\hline $\begin{array}{l}\text { Able to become quickly } \\
\text { involved in new groups. }\end{array}$ & $\begin{array}{l}4.69 \\
(0.935)\end{array}$ & $\begin{array}{l}4.67 \\
(0.966)\end{array}$ & $\begin{array}{l}4.70 \\
(0.93 I)\end{array}$ & 497.500 & -0.173 & 0.862 \\
\hline $\begin{array}{l}\text { Comfortable expressing opinions } \\
\text { in a group, even when I know that }\end{array}$ & $\begin{array}{l}4.20 \\
(0.935)\end{array}$ & $\begin{array}{l}4.05 \\
(0.92 I)\end{array}$ & $\begin{array}{l}4.26 \\
(0.944)\end{array}$ & 421.000 & -1.208 & 0.227 \\
\hline & & & & \multicolumn{3}{|c|}{$\begin{array}{l}\text { Independent samples } t \text {-test for equality } \\
\text { of means }\end{array}$} \\
\hline & & & & $\mathrm{t}$ & df & Sig (2-tailed) \\
\hline $\begin{array}{l}\text { Total comfort with communication } \\
\text { and teamwork score }\end{array}$ & $\begin{array}{l}51.31 \\
(3.717)\end{array}$ & $\begin{array}{l}50.15 \\
(5.264)\end{array}$ & $\begin{array}{l}51.76 \\
(2.84)\end{array}$ & 1.667 & 69 & 0.100 \\
\hline
\end{tabular}

Abbreviations: asymp sig, asymptotic significance; $\mathrm{df}$, degree of freedom; SD, standard deviation; sig, significance; t, t-test.

The majority of the learners in the new curriculum and several in the control group felt that IP learning was beneficial because it enabled them "to see different points of view" and "to get an understanding of a different profession's roles while learning from one another". The challenges identified included "different learning needs" and "noticeable difference in knowledge base".

3. Can you provide comments on your experience learning resuscitation skills within a group format?

Many learners in the new cardiac resuscitation curriculum felt the group format provided "a great way of learning about and from another profession", "encourages communication", and "encourages assertiveness and helps to be more confident". Many learners in the control group reported that the group learning format "helped improve communication skills" and "helped to improve team work skills", with only a few finding the format "a bit awkward".

4. Do you have any suggestions to make this module more effective for next year?
The majority of learners in both groups did not suggest any ways to improve the module. A few learners in the new curriculum made suggestions which included: "empower nurses more", "have more variation in the scenarios", and to "define roles more clearly". Some learners in the control groups responded that they would "like to have more scenarios in the lab", a suggestion made by a number of learners when the pilot project was initially evaluated.

\section{Discussion}

The $69 \%$ response rate was acceptable, given many participants had clinical commitments and could not stay to complete the surveys. Distributing the surveys prior to the end of the sessions might have resulted in improved participation rates.

The overall lack of significant findings is surprising since the experimental group had twice as much time covering the IP resuscitation curriculum than students in the control group. It is unclear whether this was due to the quality of the evaluation tools, or lack of data related to students' prior 
Table 3 Learner confidence performing cardiac resuscitation skills

\begin{tabular}{|c|c|c|c|c|c|c|}
\hline Survey item & $\begin{array}{l}\text { Overall mean } \\
\text { score } \\
\text { (SD) } \\
N=7 \mid\end{array}$ & $\begin{array}{l}\text { Control group } \\
\text { mean score } \\
(\mathrm{SD}) \\
\mathrm{N}=21\end{array}$ & $\begin{array}{l}\text { Experimental group } \\
\text { mean score } \\
\text { (SD) } \\
\mathbf{N}=\mathbf{5 0}\end{array}$ & $\begin{array}{l}\text { Mann- } \\
\text { Whitney U }\end{array}$ & $\mathbf{Z}$ & $\begin{array}{l}\text { Asymp sig } \\
\text { (2-tailed) }\end{array}$ \\
\hline $\begin{array}{l}\text { Being the team leader in } \\
\text { a cardiac resuscitation }\end{array}$ & $\begin{array}{l}4.01 \\
(0.993)\end{array}$ & $\begin{array}{l}3.90 \\
(0.944)\end{array}$ & $\begin{array}{l}4.06 \\
(1.018)\end{array}$ & 429.000 & -1.107 & 0.268 \\
\hline Managing the airway & $\begin{array}{l}4.96 \\
(0.933)\end{array}$ & $\begin{array}{l}4.33 \\
(0.856)\end{array}$ & $\begin{array}{l}5.22 \\
(0.840)\end{array}$ & 250.000 & -3.529 & 0.001 \\
\hline Doing chest compressions & $\begin{array}{l}5.46 \\
(0.556)\end{array}$ & $\begin{array}{l}5.48 \\
(0.602)\end{array}$ & $\begin{array}{l}5.46 \\
(0.542)\end{array}$ & 507.000 & -0.044 & 0.965 \\
\hline $\begin{array}{l}\text { Placing the patient on the } \\
\text { cardiac monitor }\end{array}$ & $\begin{array}{l}5.03 \\
(0.736)\end{array}$ & $\begin{array}{l}5.10 \\
(0.831)\end{array}$ & $\begin{array}{l}5.00 \\
(0.700)\end{array}$ & 488.000 & -0.312 & 0.755 \\
\hline Assessing basic cardiac rhythms & $\begin{array}{l}4.44 \\
(0.982)\end{array}$ & $\begin{array}{l}4.48 \\
(1.030)\end{array}$ & $\begin{array}{l}4.42 \\
(0.97 I)\end{array}$ & 497.000 & -0.176 & 0.860 \\
\hline Defibrillating & $\begin{array}{l}4.97 \\
(0.845)\end{array}$ & $\begin{array}{l}4.81 \\
(0.98 I)\end{array}$ & $\begin{array}{l}5.04 \\
(0.78 I)\end{array}$ & 425.000 & -1.181 & 0.238 \\
\hline $\begin{array}{l}\text { Starting an IV during cardiac } \\
\text { resuscitation }\end{array}$ & $\begin{array}{l}4.37 \\
(1.198)\end{array}$ & $\begin{array}{l}4.14 \\
(1.236)\end{array}$ & $\begin{array}{l}4.46 \\
(1.182)\end{array}$ & 464.500 & -0.609 & 0.543 \\
\hline $\begin{array}{l}\text { Administering cardiac } \\
\text { resuscitation medications }\end{array}$ & $\begin{array}{l}4.24 \\
(1.189)\end{array}$ & $\begin{array}{l}4.00 \\
(1.342)\end{array}$ & $\begin{array}{l}4.34 \\
(1.118)\end{array}$ & 400.500 & -1.454 & 0.146 \\
\hline & & & & \multicolumn{3}{|c|}{$\begin{array}{l}\text { Independent samples } t \text {-test for equality } \\
\text { of means }\end{array}$} \\
\hline & & & & $\mathrm{t}$ & df & $\begin{array}{l}\text { Sig } \\
\text { (2-tailed) }\end{array}$ \\
\hline $\begin{array}{l}\text { Total self- } \\
\text { confidence score }\end{array}$ & $\begin{array}{l}37.23 \\
(4.76)\end{array}$ & $\begin{array}{l}37.73 \\
(4.35)\end{array}$ & $\begin{array}{l}35.95 \\
(5.60)\end{array}$ & -0.353 & 67.51 & 0.725 \\
\hline
\end{tabular}

Abbreviations: asymp sig, asymptotic significance; df, degree of freedom; IV, intravenous feed; SD, standard deviation; sig, significance; t, t-test.

exposure to IP education and/or cardiac resuscitation, or to the quality of the sessions themselves. The average age of participants in the control group was 3 years older than those in the experimental group. A greater number and proportion of medical students completed the control group surveys, and it is possible that the medical students may have had more experience with cardiac resuscitation, which may have contributed to the lack of significant findings. A pre and post survey may have provided better data about the effectiveness of the sessions; however, the researchers were asked not to overburden the students with surveys, and only the post survey was conducted.

Nonetheless, results from the Communication and Teamwork survey are encouraging as they suggest that senior (4th-year) nursing and medical students feel comfortable communicating and collaborating within a team in highfidelity simulation situations. Graduating practitioners who are comfortable with IP teamwork is essential as health care professionals recognize that difficulties in this results in barriers to providing holistic patient care. ${ }^{27}$

Despite positive trends, over one-third of learners were at least somewhat uncomfortable expressing personal opinions in a group or taking the lead in a group with only a very modest improvement in the scores of the learners in the new curriculum, which suggests further emphasis needs to be placed on developing these skills during the simulation scenarios. The importance of this is highlighted in an earlier study reporting that almost two-thirds of teams of qualified health care workers failed to provide BCLS and/or defibrillation within an appropriate time window in a simulated cardiac arrest scenario. ${ }^{28}$ Absence of leadership behavior and absence of explicit task distribution were associated with poor team performance.

Results from the Confidence Performing Cardiac Resuscitation Skills survey are also encouraging in that most senior students are at least somewhat confident performing all of the cardiac resuscitation skills. It is also encouraging that nursing students feel as confident as medical students with these skills, particularly in the IP setting; however, many students are still at least somewhat unconfident performing a number of the skills, which suggests more emphasis and practice with these skills should be considered for senior students prior to licensure when they will be expected to perform these skills in practice settings. Given barriers of resources and scheduling conflicts, the addition of more simulation sessions for all students may not be feasible, but it might be possible to offer optional extra practice sessions for those learners who express a lack of confidence and need for more practice. Repetitive 
practice is one of the key features of high-fidelity simulation that leads to effective learning. ${ }^{29}$

The finding that learners in the new cardiac resuscitation curriculum were significantly more likely to report feeling confident managing the airway during cardiac resuscitation than learners in the control group suggests the additional simulation sessions contributed to confidence with this skill. Further research is needed to determine whether increasing the number of simulation sessions would increase learner confidence with the remaining resuscitation skills. Research should also look at whether improved learner confidence translates into improved skill performance in both simulated and clinical settings. Self-assessment of performance in ACLS scenarios by graduating internal medicine residents correlated poorly with their actual performance in one recent study. ${ }^{11}$

Inclusion of nursing students in cardiac resuscitation simulations is particularly important as nurses are usually the first persons to respond to a cardiac arrest and to commence basic life support. ${ }^{30}$ In one study, the majority of nurses felt their training had not prepared them to adequately deal with a resuscitation, and there was a significant difference $(P<0.001)$ for scores between nurses who had further arrest response education training and those who had not. ${ }^{31}$ Prior to the establishment of IP cardiac resuscitation rounds in 2005, nursing students at Queen's University had little hands-on preparation for participating in resuscitation. Our current IP simulation module has provided nursing students with the opportunity to practice cardiac resuscitation skills and the team leader role, and has contributed to confidence as evidenced by results of our current study. Medical students at Queen's University have previously had the opportunity to participate in cardiac resuscitation rounds while completing clinical rotations in emergency medicine. The new module, however, provides medical trainees with greater opportunity to practice in an IP setting that mimics real-life clinical situations.

Results of the qualitative Interprofessional Learning survey indicate that the majority of nursing and medical trainees report feeling comfortable learning with students from other professions and found value in the IP simulation sessions. It is encouraging that learners identified improved communication skills, improved teamwork skills, and understanding a different profession's role as benefits of the IP session, as these were the main IP objectives for the course. Participants had few suggestions of how to improve the module, suggesting that they were satisfied with the simulation sessions.
Limitations to this study include a small sample size, a smaller control group compared with the experimental group, and nonrandomization which may have contributed to the lack of significant differences. Overall, a disproportionate number of medical trainees did not complete the survey, which may have influenced the results. Lack of data related to the learners' previous experience with IP learning and cardiac resuscitation was another limitation. Learners in both the control group and the new curriculum had some IP classes in the past that may have influenced findings related to the IP outcomes in this study. Medical students may have had sessions on cardiac resuscitation during other clinical rotations prior to their emergency medicine rotation. Learner attitudes and confidence were not surveyed prior to participation in the educational module, thus it is unclear how much of their reported comfort and confidence were attributable to prior learning activities.

\section{Conclusion}

A larger action research project led to the development and implementation of a cardiac resuscitation skills lab, and increased IP team training for senior nursing and medical students. This simulation module has been successfully integrated into the curricula of the Schools of Nursing and Medicine at Queen's University. Despite positive trends observed in this study, due to the lack of significant findings we do not have enough evidence to say that the addition of the skills lab and an additional week of cardiac resuscitation rounds using simulation made a significant difference to the comfort with IP collaboration or to their confidence performing cardiac resuscitation skills; however, positive feedback from our graduates, clinical faculty, and our partner clinicians indicates an improvement in our new graduates in handling emergency situations. Evaluation of learner performance is ongoing and will provide important additional evidence regarding the IP cardiac resuscitation curriculum.

Results from this study will inform ongoing restructuring of the IP cardiac resuscitation skills simulation module as defined by the action research process. Specific improvements that are suggested by these findings include strengthening the team leader component of the resuscitation skills lab and identifying learners who may benefit from additional practice in the role of team leader and with other skills where they lack confidence. Further research should investigate the optimum number of simulation sessions necessary for senior nursing and medical students to acquire adequate team leader skills and confidence with cardiac resuscitation skills. 


\section{Acknowledgments/disclosure}

The authors report no conflicts of interest in this work. This research study was funded by a grant from the Ontario Ministry of Health and Long-Term Care, Health Education Innovation Fund. The researchers would also like to thank Robert Stevenson, BSc, P Eng, the OIPEP at Queen's University, and the nursing and medical students who participated in the study.

\section{References}

1. Laschinger S, Medves J, Pulling C, et al. Effectiveness of simulation on health profession students' knowledge, skills, confidence and satisfaction. Int J Evid Based Healthc. 2008;6:278-302.

2. Adams DA, Dobbs J, Greene M, MacGillis PA, Stockhausen PA. A model to enhance staff response in cardiopulmonary arrest. J Nurs Care Qual. 2002;17(1):43-50.

3. Linnard-Palmer LR. The effect of a skills algorithm on nursing students' response rate, skill accuracy, and reported attentional management during simulated cardiopulmonary arrests: a dissertation. San Francisco: The University of San Francisco; 1996.

4. Moser DK, Coleman S. Recommendations for improving cardiopulmonary resuscitation skills retention. Heart Lung. 1992;21(4): 372-380.

5. Kuhnigk H, Sefrin P, Paulus T. Resuscitation skills of hospital nursing staff. Eur J Emerg Med. 1994;1(4):193-198.

6. Dunning J, Nandi J, Ariffin S, Jerstice J, Danitsch D, Levine A. The cardiac surgery advanced life support course: delivering significant improvements in emergency cardiothoracic care. Ann Thorac Surg. 2006;81:1767-1772.

7. Hagyard-Wiebe T. Should critical care nurses be ACLS-trained. CACCN. 2007;18(4):28-31.

8. Hamilton R. Nurses' knowledge and skill retention following cardiopulmonary resuscitation training: a review of the literature. JAdv Nurs. 2005;51(3):288-297.

9. Long RE. Using simulation to teach resuscitation: an important patient safety tool. Crit Care Nurs Clin N Am. 2005;17:1-8.

10. Wayne DB, Butter J, Siddall VJ, et al. Simulation-based training of internal medicine residents in Advanced Cardiac Life Support protocols: a randomized trial. Teach Learn Med. 2005;17(3):210-216.

11. Wayne DB, Butter J, Siddall VJ, et al. Graduating internal medical residents' self-assessment and performance of advanced cardiac life support skills. Med Teach. 2006;28(4):365-369.

12. Wayne DB, Siddall VJ, Butter J, et al. A longitudinal study of internal medicine residents' retention of advanced cardiac life support skills. Acad Med. 2006;81(10):S9-S12.

13. Wayne DB, Didwania A, Feinglass J, Fudala MJ, Barsuk JH, McGaghie WC. Simulation-based education improves quality of care during cardiac arrest team responses at an academic teaching hospital: a case-control study. Chest. 2008;133:56-61.
14. Smith HM, Jacob AK, Segura LG, Dilger JA, Torsher LC. Simulation education in anesthesia training: a case report of successful resuscitation of bupivicaine-induced cardiac arrest linked to recent simulation training. Anesth Analg. 2008;106(5):1581-1584.

15. Nyman J, Sihvonen M. Cardiopulmonary resuscitation skills in nurses and nursing students. Resuscitation. 2000;47:179-184.

16. Seraj MA, Naguib M. Cardiopulmonary resuscitation skills of medical professionals. Resuscitation. 1990;20:31-39.

17. Weller J, Robinson B, Larson P, Caldwell C. Simulation-based training to improve acute care skills in the medical undergraduates. $N Z$ Med J. 2004;117(1204):1-8.

18. Eyck RPT, Tews M, Ballester JM, Hamilton GC. Improved forth-year medical student clinical decision-making performance as a resuscitation team leader after a simulation-based curriculum. Simul Healthc. 2010;5(3):139-145.

19. Coates V, Andrews J, Davies M, et al. An evaluation of multi-professional education in diabetes. J Interprof Care. 2008;22(3):295-307.

20. Cook DA. Models of interprofessional learning in Canada. J Interprof Care. 2005;19 Suppl 1:107-115.

21. Institute of Medicine. To Err is Human: Building a Safer Health System. Washington, DC: National Academy Press; 2000.

22. deVita MA, Schaefer J, Lutz J, Wang H, Dongilli T. Improved medical emergency team (MET) performance using a novel curriculum and a computerized human patient simulator. Qual Safe Healthc. 2005; 14:326-331.

23. Bradley P, Cooper S, Duncan F. A mixed-methods study of interprofessional learning of resuscitation skills. Med Educ. 2009;43(9): 912-922.

24. Perkins GD, Hulme J, Bion JF. Peer-led resuscitation training for healthcare students: a randomised controlled study. Intensive Care Med. 2002;28(6):698-700.

25. Dagnone JD, McGraw RC, Pulling CA, Patteson AK. Interprofessional resuscitation rounds: A teamwork approach to ACLS education. Med Educ. 2008;30:e49-e54.

26. Pollard KC, Miers ME, Gilchrest M. Collaborative learning for collaborative working? Initial findings from a longitudinal study of health and social care students. Health Soc Care Community. 2004; 12(4):346-358.

27. Kvarnstrom S. Difficulties in collaboration: a critical incident study of interprofessional healthcare teamwork. J Interprof Care. 2008;22(2): 191-203.

28. Marsch SCU, Muller C, Marquardt K, Conrad G, Tschan F, Hunziker PR. Human factors affect the quality of cardiopulmonary resuscitation in simulated cardiac arrests. Resuscitation. 2004;60(1):51-56.

29. Issenberg SB, McGaghie WC, Petrusa ER, Gordon DL, Scalese RJ. Features and uses of high-fidelity medical simulations that lead to effective learning: a BEME systematic review. Med Teach. 2005; 27(1):10-28.

30. McKee DR, Wynne G, Evans TR. Student nurses can defibrillate within 90 seconds. Resuscitation. 1994;27:35-37.

31. O'Donnell C. A survey of opinion amongst trained nurses and junior medical staff on current practices in resuscitation. J Adv Nurs. 1990; $15: 1175-1180$.
Advances in Medical Education and Practice

\section{Publish your work in this journal}

Advances in Medical Education and Practice is an international, peerreviewed, open access journal that aims to present and publish research on Medical Education covering medical, dental, nursing and allied healthcare professional education. The journal covers undergraduate education, postgraduate training and continuing medical education

\section{Dovepress}

including emerging trends and innovative models linking education, research, and healthcare services. The manuscript management system is completely online and includes a very quick and fair peer-review system. Visit http://www.dovepress.com/testimonials.php to read real quotes from published authors. 